\title{
Seismic Modeling Constraints on the South African Super Plume
}

\author{
Don V. Helmberger and Sidao Ni \\ Seismological Laboratory, California Institute of Technology, Pasadena, California
}

\begin{abstract}
Tomographic studies of the structure of the lower mantle beneath South Africa reveal large-scale low velocities above the core-mantle boundary. Predicted SKS delay patterns (up to $3 \mathrm{~s}$ ) for some of these models fit observations (Kaapvaal Array data) quite well except for magnitude level, explaining less than one-half the observed anomaly. Moreover, the sharpness in travel-time offsets and waveform complications require that nearly vertical walls separate the anomalous structure from the normal preliminary reference Earth model (PREM) mantle. We present numerous record sections along with 2D and 3D synthetics displaying multipathing of arrivals $\left(\mathrm{S}_{\mathrm{d}}\right.$, SKS, SKKS, S, and $\left.\mathrm{ScS}\right)$, based on a large-scale 3D structure. This kidney-shaped structure has one apex beneath the Indian Ocean (Kerguelen) and the other extending beneath the Mid-Atlantic (Cape Verde). The structure is about $1200 \mathrm{~km}$ wide beneath South Africa and extends upward to at least $1000 \mathrm{~km}$ through the lower mantle, similar to Grand's model but with an average uniform velocity decrease of about 3\% relative to PREM. We have not found any evidences for ultra-low-velocity zones (ULVZ) beneath the main structure but ample evidence at some locations near the edges. We also analyzed Pd and the differentials between $\mathrm{PcP}$ travel times and $\mathrm{P}$ travel times $(\mathrm{PcP}-\mathrm{P})$ along the same great circle paths from the same events. The P-velocity is not very anomalous, perhaps $-0.5 \%$. The sharpness of the lateral boundaries (walls) and the large contrast in $\mathrm{P}$ and $\mathrm{S}$ velocities can be used in arguments for a thermochemical origin.
\end{abstract}

\section{INTRODUCTION}

The large-scale structures in the lower mantle have been well established in recent years, e.g., reviewed by Garnero [2000]. While the details may differ, most tomographic inversions yield a relatively fast region around the circum-Pacific belt with some complex patterns of slow velocities centered beneath the Mid-Pacific and South Africa. This picture of the mantle is consistent with the fast regions being cold and generated by past subduction [Grand, 2002]. The warm colors are attributed to upwelling, contain most of the world's hot-

Earth's Deep Mantle: Structure, Composition, and Evolution Geophysical Monograph Series 160 Copyright 2005 by the American Geophysical Union 10.1029/160GM06 spots, and correlate with the long-wavelength geoid highs [Hager et al., 1985]. Sharper seismic structures have been revealed with P-wave tomography [van der Hilst et al., 1996] and with shear velocity tomography based on bodywaves [Grand, 1994]. The agreement between these two models for the upper $2000 \mathrm{~km}$ of the mantle is remarkable considering the complete independence of data and methodology [Grand et al., 1997]. At greater depths, the relationship between $P$ and $\mathrm{S}$ becomes more complex, indicating possible chemical influences [van der Hilst et al., 2004].

The cause of the disagreement at greater depths is under investigation but the bulk sound velocity $\left(V_{\mathrm{c}}\right)$ appears to be negatively correlated with $V_{\mathrm{s}}$ within the African and Pacific anomalies [Masters et al., 2000]. The most definitive data on the African structure come from the observations of 
diffracted S-waves, $S_{d}$, compared to $P_{d}$ at the broadband African Array, from the same events [Wen, 2001]. While $P_{d}$ appears PREM-like across the array, $S_{d}$ develops sharp delays of up to $20 \mathrm{~s}$ for many samples. Wen [2001] was able to model many of these waveforms in $2 \mathrm{D}$ by introducing very low shear velocities at the base of the mantle with rapid variations at the edges of the anomaly.

The focus of this review is a detailed examination of the African superstructure as imaged by forward modeling. To develop the model, we started with Grand's tomographic model (Plate 1) and added sharp detail along line segments. Much of its sharpness is due to this style of enhancing Grand's tomography model. Note that the bottom basal layer is essentially Grand's, with a uniform 3\% velocity reduction in $\mathrm{D}^{\prime \prime}$. The structure above $\mathrm{D}^{\prime \prime}$ is more anomalous than Grand's, extending upward to about the depth of 1700 $\mathrm{km}$, where the velocity inside the structure has been uniformly decreased by $3 \%$ relative to PREM [Dziewonski and Anderson, 1981], but keeping Grand's model elsewhere. This simplistic model has evolved with the addition of new data, especially the recently released Kaapvaal Array data [James et al., 2001]. A 2D section along a path from South America to the African Array is displayed in Plate 2B. The upper panel (Plate 2A) displays the locations of some of the events used in developing the model, including those providing the waveforms discussed in this review.
The lower panel (Plate 2C) shows the SKS delays as augmented by the African Array roughly outlining the anomalous structure [Ni and Helmberger, 2003a]. Note that sharp walls produce rapid jumps in SKS travel times since their ray paths (Plate 2B) can travel nearly parallel to these boundaries. These sharp features can also be effective in delaying $\mathrm{ScS}$ relative to S. A record section of a South American event (971128) is displayed in Figure 1 as a typical example of such (ScS-S) complexity, along with 2D synthetics for the tomographic models by Grand [1994] and Ritsema et al. [1999] and our model LVZ2, based on a low-velocity zone (LVZ) (Plate 2B). These synthetics were generated with the WKM technique introduced in Ni et al. [2000]. The method is basically analytical, which satisfies the wave equation assuming tomographic-type models. A comparison of synthetic seismograms for the model displayed in Figure 1 , using the above semi-analytical code with a 2D numerical technique, is given in Ni et al. [2003d].

The beginning portion of this data set (ranges $85^{\circ}$ ) samples the westernmost edge of the model, along the dashed line in Plate $2 \mathrm{~A}$. There is ample evidence for a complex LVZ starting below about $40^{\circ}$, indicated by the green lines [Wen et al., 2001; Ni and Helmberger, 2001]. Thus, the complexity of ScS was not modeled well by LVZ2 since we omitted this smallscale feature. However, the model predicts the separation of (ScS-S) quite well at larger distances. The LVZ2 model

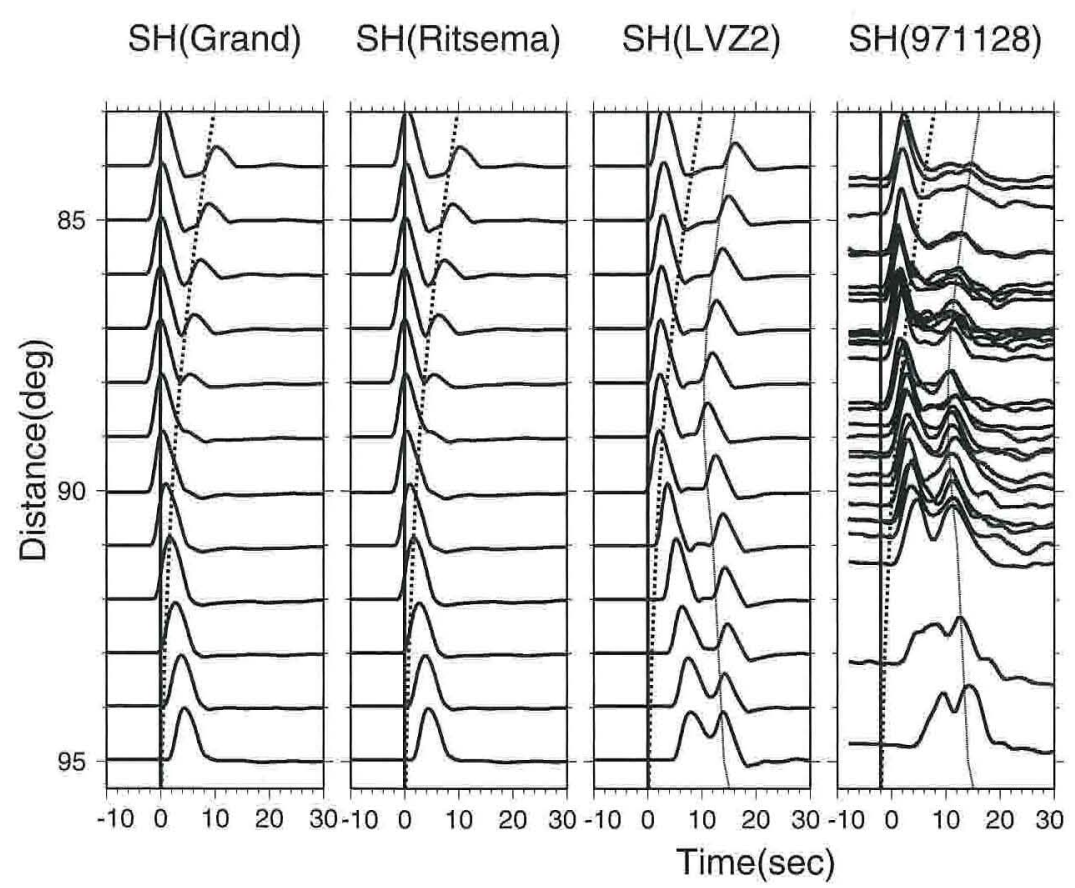

Figure 1. Comparison of data (right) against synthetic predictions from tomographic models and the hybrid model (LVZ2) displayed in Plate 2. These sections are aligned on the S-wave times predicted by PREM. The corresponding ScS times are shown as a dotted line; a heavy line indicates the observed ScS peak arrival time for comparison. 

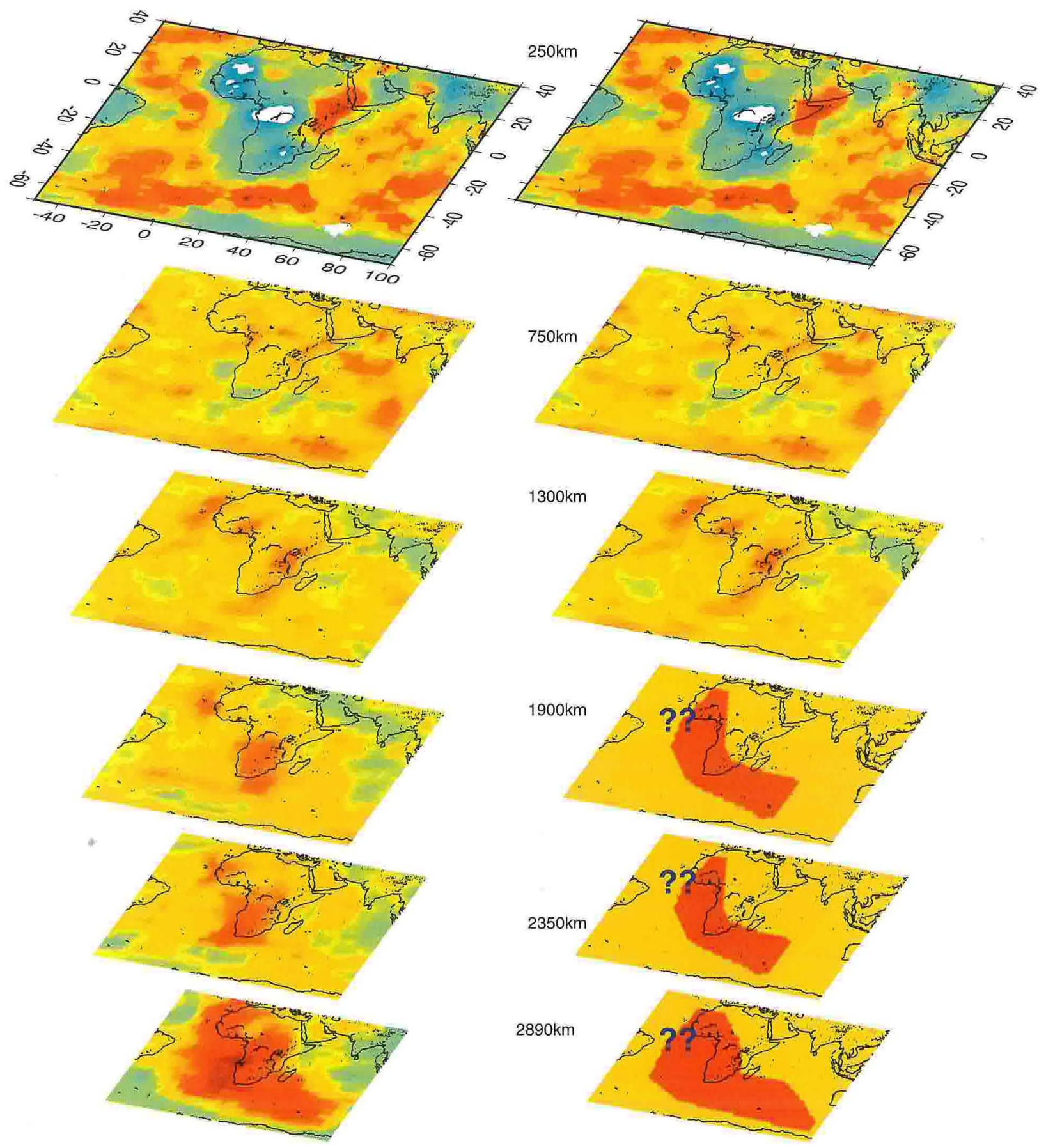

Plate 1. Panels on the left are tomography results from Grand [2002] as a function of depth (Z). The colors represent positive (blue) and negative (red) anomalies $( \pm 4 \%)$. The model on the right is Grand's model except for the solid red zone beneath Africa. We will call this hybrid model ALVS (African Low Velocity Structure), which has a uniform 3\% reduction in S-velocity and PREM in P-velocity. 

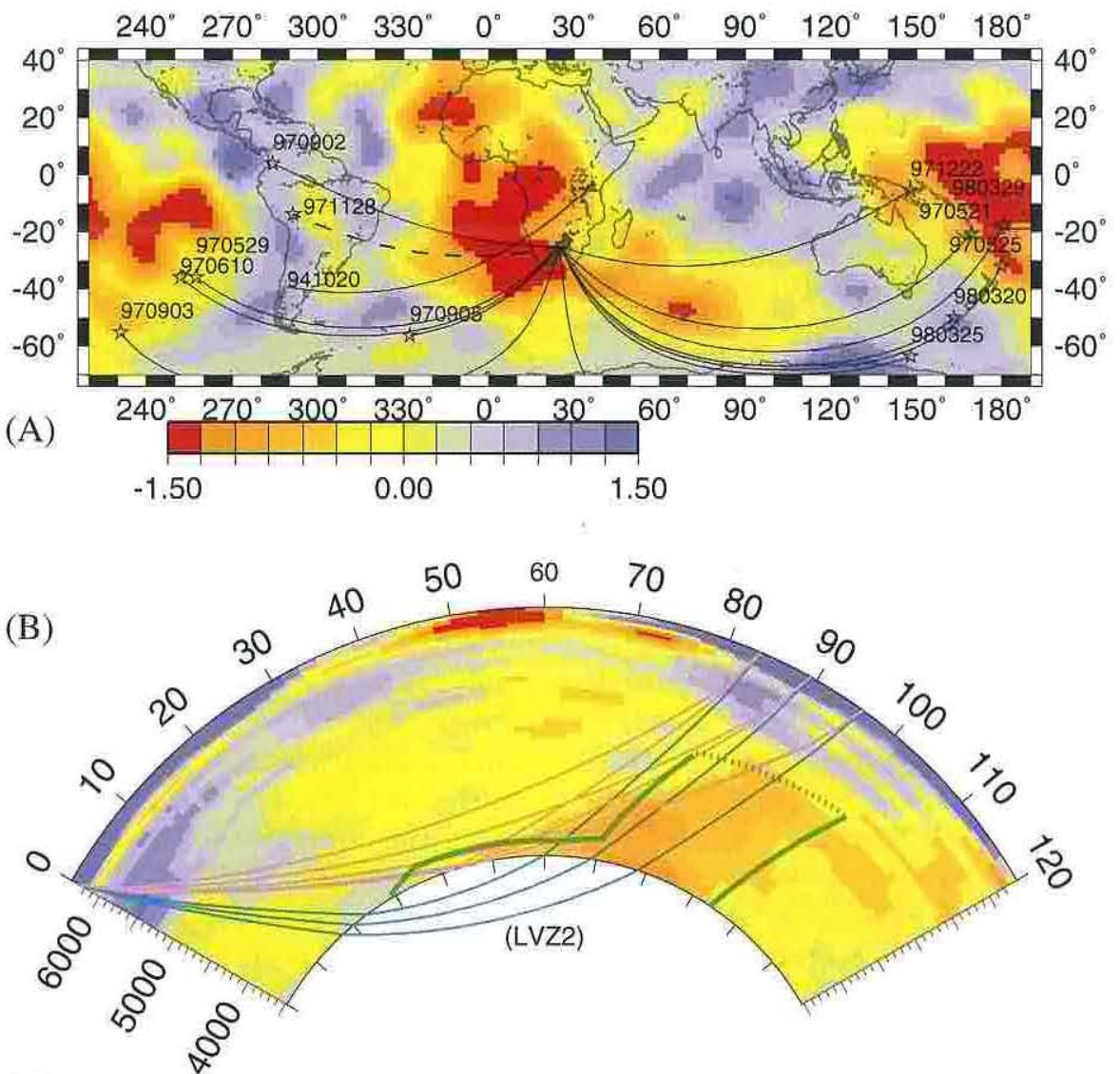

(C)

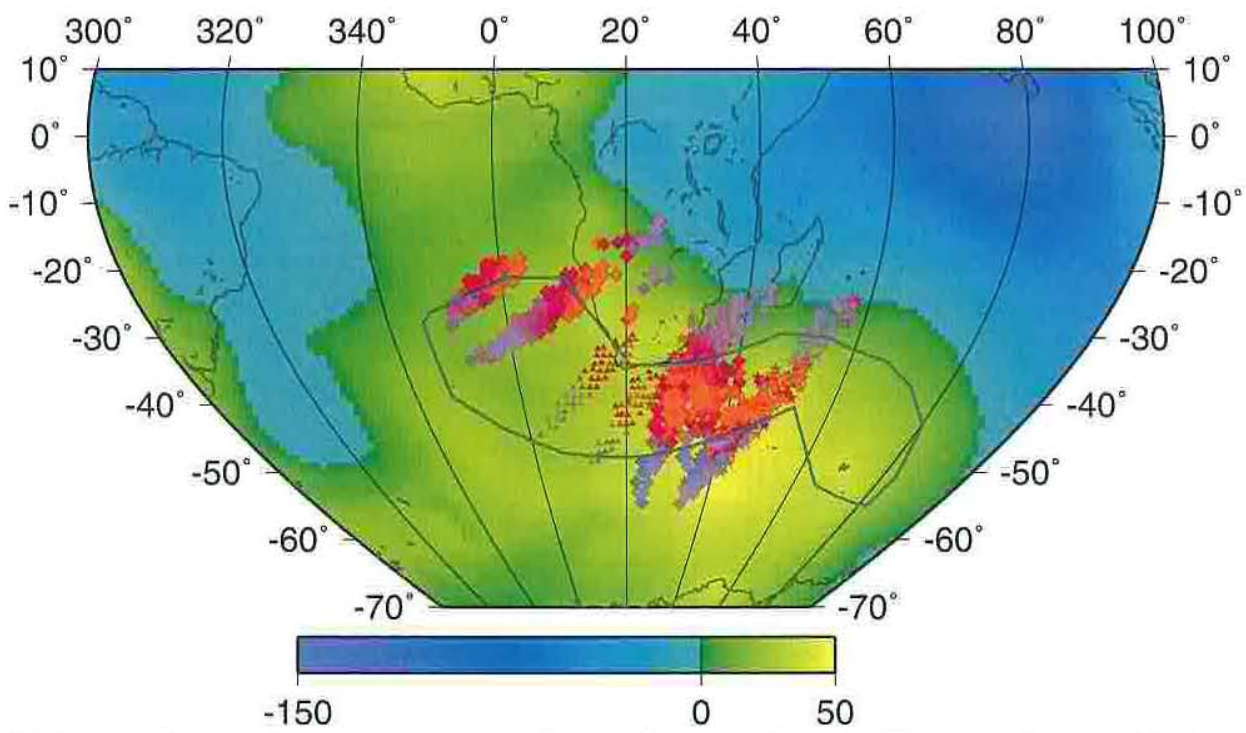

Plate 2. (A) Display of a map of events (open stars) along with some paths to the Kaapvaal Array and the Tanzania Array (solid triangles) superimposed on the tomographic results of Ritsema et al. [1999]. (B) Cross-section along a path from event 971128 , denoted as a dashed line in the tomographic model. The hybrid model (LVZ2) is denoted by the heavy green lines. Ray paths are included for S and ScS (magenta) and SKS (blue). (C) SKS and SKKS exit points at the CMB; delays of more than $5 \mathrm{~s}$ are shown in magenta, those of 0 s (i.e., no delay) in blue. The colored background indicates the observed geoid in meters. The Dupal geochemical anomaly is outlined in dark blue (after Hart [1984]). 

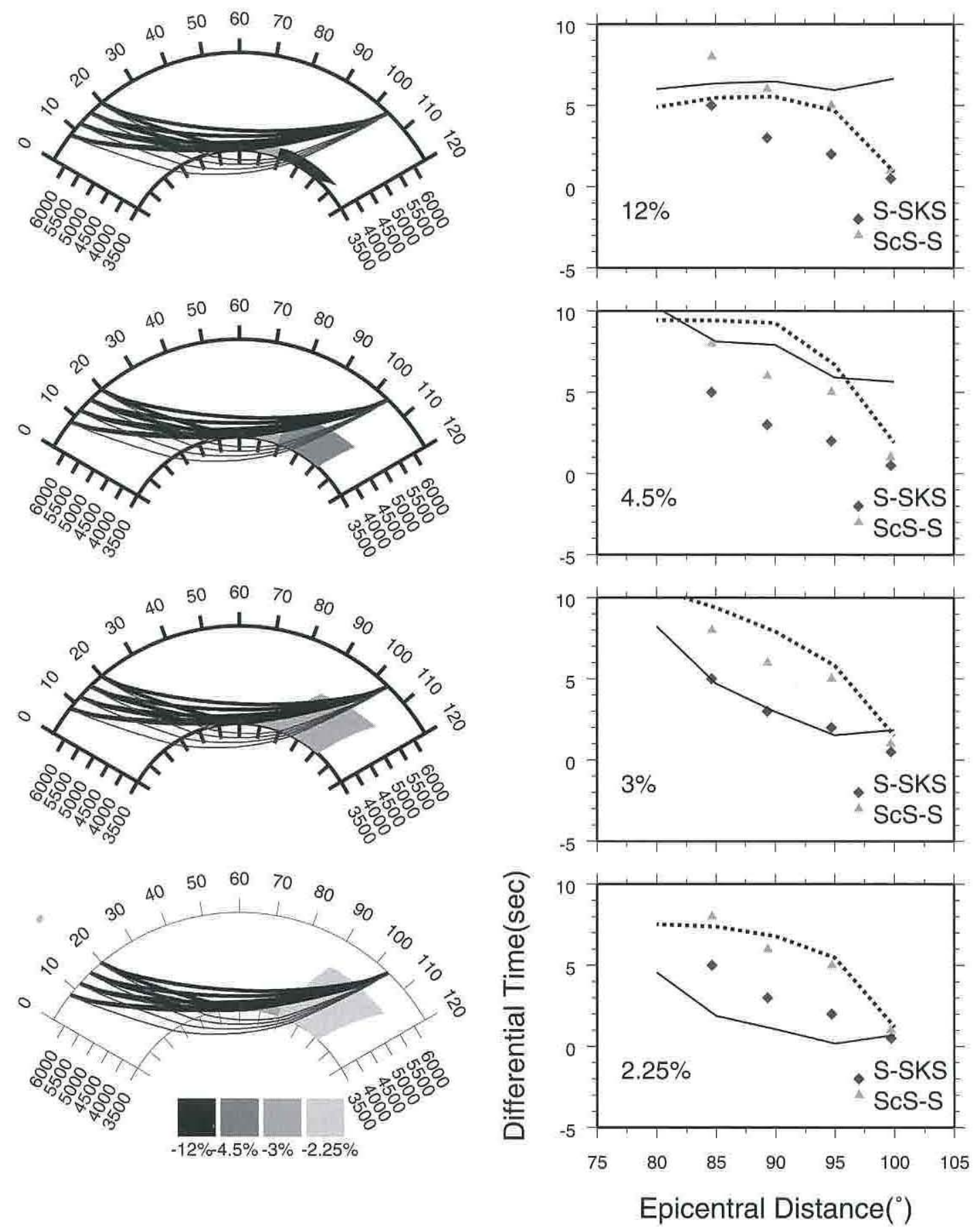

Figure 2. ALVS thickness sensitivity testing. Cross-sections with various thicknesses are presented on the left, along with ray paths where the travel times of SKS have been preserved. The basal layer on the left $\left(\mathrm{D}^{\prime \prime}\right.$ beneath the Atlantic) is maintained at $3 \%$. The ALVS thickness varies from $300,1000,1500$, and $2000 \mathrm{~km}$, with velocity reductions at $12 \%$ to $2.25 \%$. The associated differential travel time predictions (SKS-S) and (ScS-S) are displayed on the right, along with the data observed at the IRIS station LSZ (see Plate 3a for location), after Ni and Helmberger [2003a]. 
was derived from the IRIS and older WWSSN data [Ni and Helmberger, 2003b] before the Kaapvaal Array data were released. The model was developed largely by trial and error analysis of multi-events recorded by individual stations as displayed in Figure 2 for station LSZ. This station, located about halfway between the two arrays (Plate 3), recorded S, $\mathrm{ScS}$, and SKS from many events, four events being selected as representative along a narrow South American corridor (segment A) in Plate 3 [Ni and Helmberger, 2003b]. Four representative models with heights constrained at 2000 , 1500,1000 , and $300 \mathrm{~km}$ with roughly equal SKS delays of $6 \mathrm{~s}$ are displayed. Note that $\mathrm{S}$ is delayed too much for the $2000-\mathrm{km}$ case and SKS-S becomes too small to fit the data, but with thinner structures SKS-S becomes too large. Thus, the combination of ( $\mathrm{ScS}-\mathrm{S}$ ) and (SKS-S) proves quite useful in constraining possible models.

The introduction of lateral variation on a variety of scales and magnitudes allows reasonable fits to limited data but unfortunately exasperates the uniqueness question. Addressing this issue of uniqueness is one of the major efforts of this review. For example, if we reinterpret Figure 2 with the boundary moved westward, we would reach a different conclusion above the preferred height. Thus a thinner layer but with a stronger velocity drop could equally fit these data, as interpreted by Wang and Wen [2004]. While the above strategy produced a modification of Grand's model, Wen et al. [2001] explains the Kaapvaal Array data by attributing all the low-velocity structure to $\mathrm{D}^{\prime \prime}$ and adopting PREM elsewhere. A rough outline of the boundary derived from this strategy is displayed in Plate 3. Much of its position is similar to that derived by Grand [2002; Plate 1] and is adopted into our model as a uniform (3\%) slow shear-wave layer. In contrast, the $\mathrm{D}^{\prime \prime}$ model of Wen et al. [2001] becomes highly variable where they break up array data into sectors with separate 2D models for each. Many of the synthetics produced by following their strategy fit observations very well and probably capture some of extreme variability in the real Earth. Our working approach has been to limit the number of parameters as much as possible by keeping a uniform drop in shear velocity and using numerous stations and events to set the position of the lower-mantle geography.

Our African Low Velocity Structure (ALVS) model has two branches; one extending northwestward beneath the Atlantic (Western Province) and another beneath the Indian Ocean (Eastern Province). The former has better sampling because of the richness of seismicity to the west, as displayed in Plate 2. However, there are hardly any stations in North Africa, and our model to the north becomes less defined for this reason.

The sequence of events along the great-circle path through Sandwich Island is especially well-sampled [Ritsema et al., 1998a]. The addition of the Kaapvaal Array makes this corridor even more attractive for this in-depth review.

\section{STRUCTURAL DEFINITION OF THE WESTERN PROVINCE}

We begin this section with a detailed cross-section study along a great-circle path through South Africa. The events span about $80^{\circ}$, ranging from the East Pacific Rise (EPR) to South Sandwich Island (see Plate 3A). The stations include the two arrays, Kaapvaal and Tanzania, and the more distant IRIS stations, FURI and ATD. Events arriving from the northeast recorded along this profile are not very anomalous except for a small delay of SKS relative to $S$ as they travel about the same distance in the ALVS [Ritsema et al., 1998a].

Ray paths for the various phases are displayed in Plate $3 \mathrm{~B}$, including path segments for diffracted $\mathrm{S}_{\mathrm{d}}$ (red) and SKS (blue) for two EPR events that sample the western boundary near position $\mathrm{b}$. In this section, we will examine in detail the behavior of SKS delay jumps at the boundaries, followed by a discussion of $S_{d}$ and $P_{d}$ from an EPR event. Next, we address $\mathrm{ScS}$ bounce-points sampling across the western boundary at position $b$. Last, we examine the uniformity issue by examining S-waves turning at various depths in the ALVS model.

\section{Jumps in SKS}

The SKS ray paths are nearly vertical as they approach the array and therefore are useful in detecting horizontal velocity variations. A record section of the 970529 (EPR) events (Figure 3 ) displays a remarkable jump in travel time at the western boundary. Even though the records of this shallow event are complicated, they align well by applying a waveform correlation routine (column 2). The line segments included in the figure correspond to arrival times predicted by PREM from $93^{\circ}$ to $101^{\circ}$ (sampling outside the structure) followed by a second line segment $5 \mathrm{~s}$ later from $102^{\circ}$ to $110^{\circ}$ (inside structure). This jump is 10 times larger than array station delays (S-waves) reported by James et al. [2001]. The differential times between these arrivals and PREM predictions are displayed on the right, where we have subdivided the stations into two groups to indicate some small-scale feature towards the interior of the structure. The predicted times from the model are included for comparison. Other paths such as those from event 970903 (Plate 2) show a similar jump with some waveform complexity at the boundary indicative of some slow material either at the CMB or along the wall, which will be discussed later.

The SKS delays from the various events are given in map view at the $\mathrm{CMB}$ by projecting the rays to their piercing points (Plate 2C). Note, however, that these data do not constrain the 
height of the structure since travel times trade-off with velocity; rather, they simply define the edge of the boundary and magnitude of the anomaly (about $6 \mathrm{~s}$ ) starting at position $\mathrm{b}$. Note that introducing a very low velocity layer from $b$ to $c$ (Plate 3B) could explain these particular data with the entire anomaly within the $\mathrm{D}^{\prime \prime}$ layer. To compare our results with those of Wang and Wen [2004], we will construct an alternative model, ULVD, specified by a thickness of $300 \mathrm{~km}$ with a velocity reduction of $2 \%$ at the top, grading to a $12 \%$ drop at the CMB. We will suppose that the boundary is the same as the above ALVS.

\section{Diffracted $S d$ and $P d$}

The $S_{d}$ phase from the above event (970529) is weak but this phase is quite strong for a neighboring event (970610) located about $3^{\circ}$ further away. These data are displayed in Figure 4 , where the ray paths began to sample the top of the anomaly at about $103^{\circ}$, which is $3^{\circ}$ further away than observed in Figure 3, as predicted. The delays are gradual but reach values over $8 \mathrm{~s}$ at the largest distances. Since the $S_{d}$ has a smaller ray parameter than SKS and a longer path length in the ALVS, we would expect these phases to be delayed more than SKS. In contrast, the ULVD model remains unsampled throughout the section, with no predicted delays (see Figure 4D). However, if we placed a ULVZ in $D^{\prime \prime}$ starting near $105^{\circ}$ (to the west of b), we could produce the observed delay but then it would be seen in SKS - which it is not. Note that only structures near the ray segments shown have any effect on this differential behavior since the structure beneath South America is
970529, aligned on IASP91

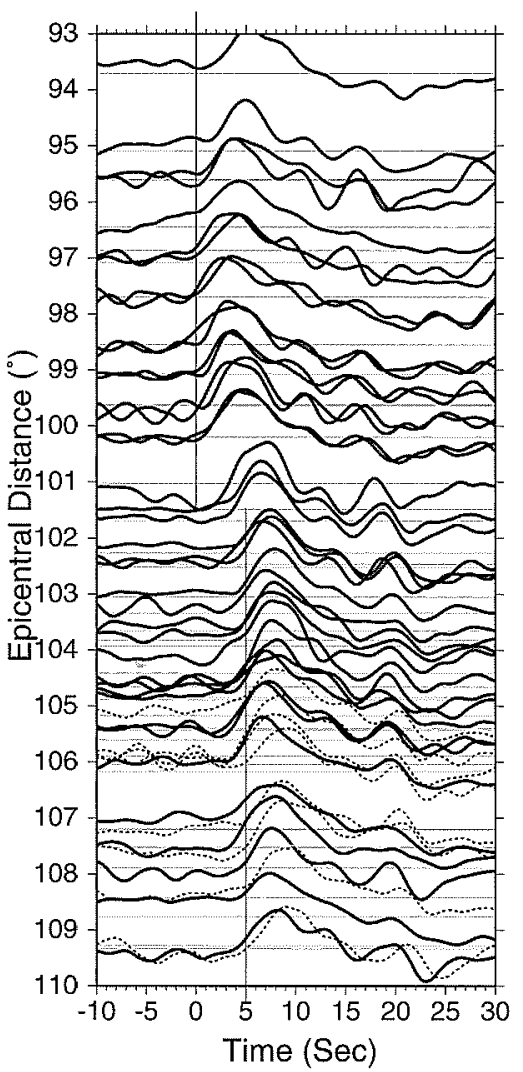

970529, aligned with arrival

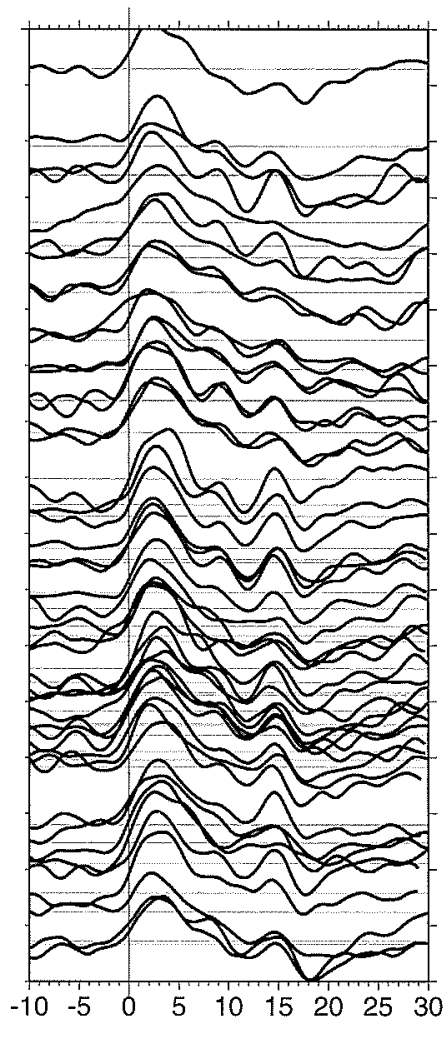

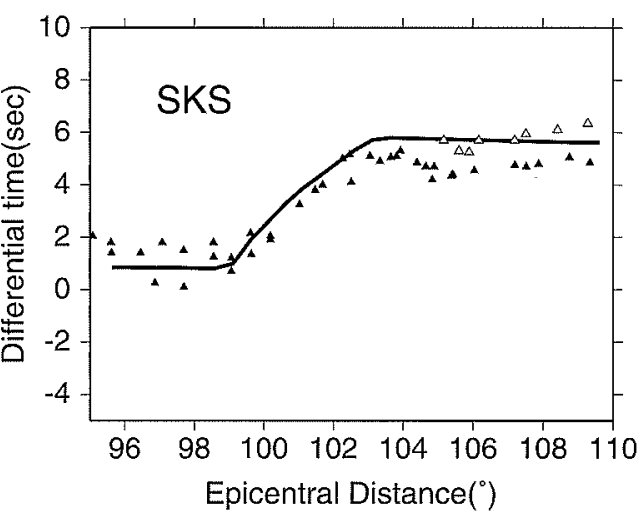

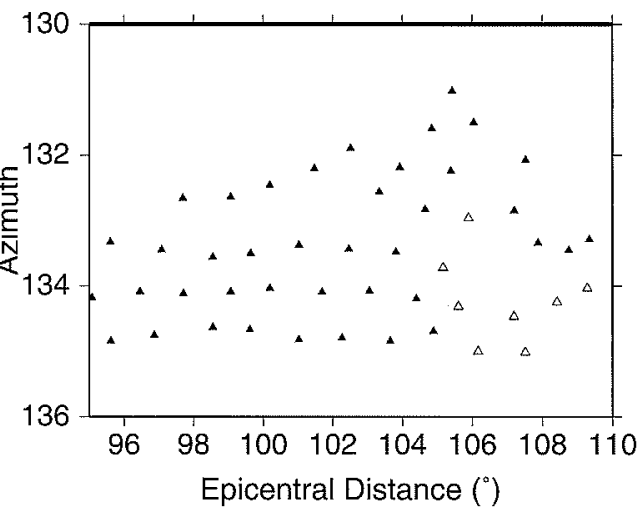

Figure 3. Displays of Kaapvaal Array data obtained from the shallow East Pacific Rise event before and after shifting, as displayed on the left and middle panels. The column on the left indicates the data plotted relative to PREM, where the upper half of the data reflect normal arrival times relative to late arrivals beyond about $100^{\circ}$. Heavy lines indicate the apparent offsets. Smaller-scale differences are indicated in the bottom half as a combination of solid and dashed traces, the latter indicating a small delay of a few seconds. The upper right panel displays delays in the travel time determined by cross-correlation for this event relative to PREM. Open triangles indicate the small-scale variation associated with the northernmost array stations as shown in the lower panel. Note how close these paths must be and still have different arrival times. 

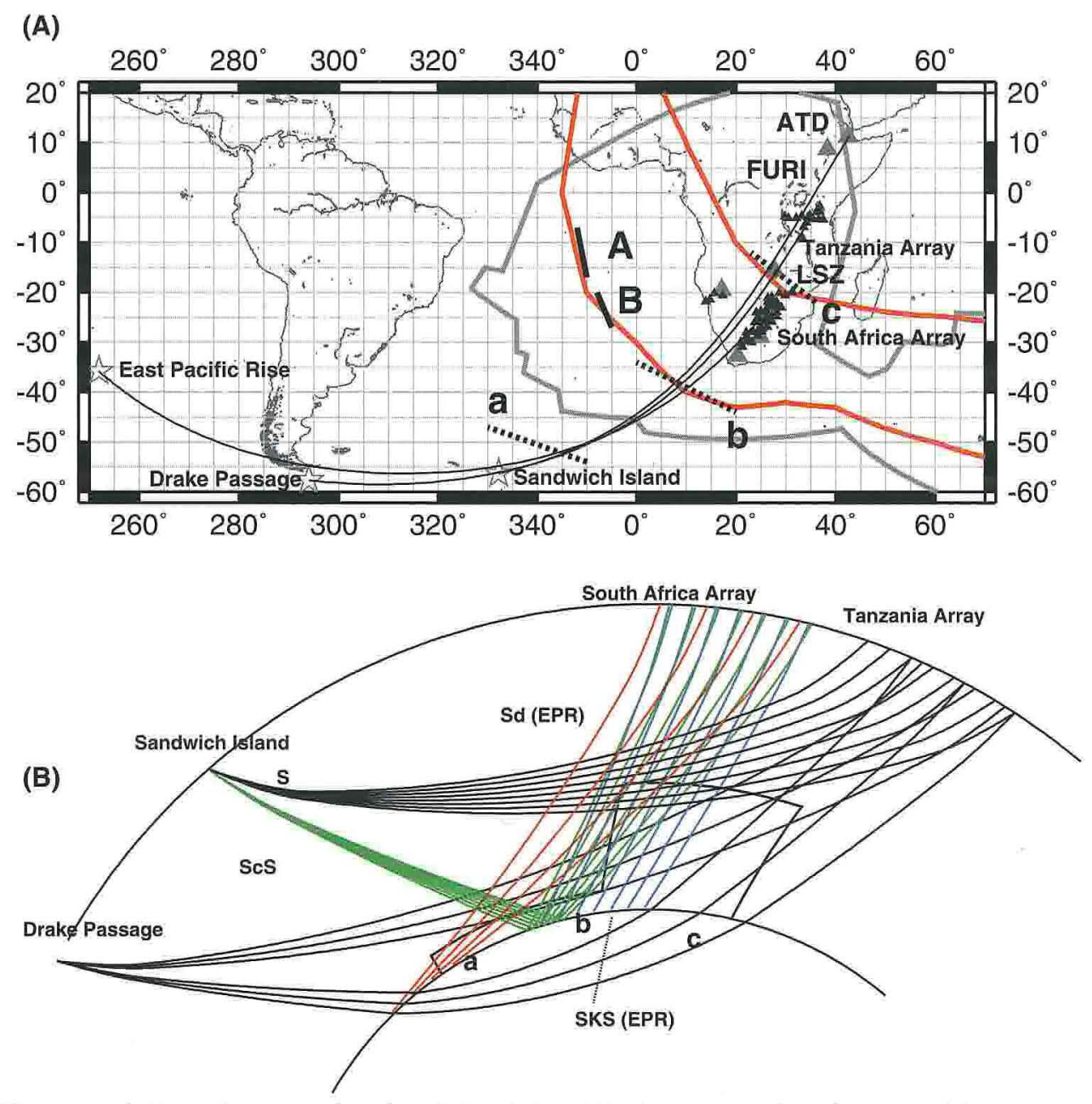

Plate 3. Upper panel: Map of events and stations (triangles) used in the construction of a 2D corridor. Lower panel: Ray paths from the various events relative to the 2D structure. Note that location (a) is at the ALVS onset where an ULVZ has been reported, and (b) and (c) indicate the upper structural boundaries. We have included the up-going $\mathrm{S}_{\mathrm{d}}$ and SKS ray paths from two East Pacific Rise (EPR) events, after Ni and Helmberger [2003b]. Segments A and B in the upper map indicate the azimuths sampled by data presented in Figures 2 and 1, respectively. 
common to all these $S_{d}$ phases. Thus, the combination of SKS and $\mathrm{S}_{\mathrm{d}}$ is providing some resolution on the position of the boundary and height of the structure.

We also measured $P_{d}$ times with the correlation code for the above event and found only small delays, in agreement with the earlier study by Wen et al. [2001]. These data are rather unique in that they involve the same event and have nearly common paths (Figure $4 \mathrm{~F}$ ). The data are more extreme at the larger ranges than predicted by the ALVS model, which could mean that the midstructure is either slower or extends upward.

\section{Differential Times Between $S c S-S$ and $P c P-P$}

Another excellent constraint on the western boundary is provided by $\mathrm{SeS}-\mathrm{S}$ and $\mathrm{PcP}-\mathrm{P}$ observations recorded by the African Array from South Sandwich Island events. Much of the data have been discussed in Simmons and Grand [2002]. They found that while $\mathrm{ScS}-\mathrm{S}$ produces a strong anomaly, PcP-P estimates were only slightly anomalous. Their datasets involved different earthquakes so that the $\mathrm{P}$ and $\mathrm{S}$ ray paths could be slightly different. Ni and Helmberger [2003b,c] expanded their study once the African Array data were released. They report on an event (970602) that had highquality $\mathrm{P}$ and $\mathrm{S}$ waves with the travel-time differentials displayed in Figure 4E. The PcP-P differentials do not change much throughout the array with perhaps a 1.5-s delay. The small shift of about $2 \mathrm{~s}$ relative to PREM can be attributed to the slow $\mathrm{D}^{\prime \prime}$ basal layer (3\%). That is, the direct P and S for this dataset have their turning depths above the anomaly (Plate 3 ) and have travel times similar to PREM; thus only $\mathrm{ScS}$ samples the structure.

Simmons and Grand [2002] interpreted their results in terms of a melt zone which would be compatible with the ULVD panel (see Figure 4B). Although this shift of the ULVD towards the west could explain the data, it now would disagree with where the SKS phases have their jump. Thus, geometry becomes extremely important in resolving these issues and in the need to investigate the whole family of S phases to provide sampling. Note that accomplishing the detailed resolution attempted here relies on the great-circle paths. To do this in 3D becomes very difficult, and using existing tomographic models as a guide is useful. We will address this issue in the next section, where we discuss the evolution in models leading to the above structure.

\section{Structural Uniformity}

One of the first PASSCAL experiments in Africa was located in Tanzania [Nyblade et al., 1996]. Its purpose was to study the East African Rift System and, therefore, was not ideal for deep earth studies. However, Ritsema et al. [1998b] have established the station delays caused by the upper mantle, which range from 3 to $4 \mathrm{~s}$ for S-waves. Before these data were released, we were working on explaining the existing WWSSN (analog) data and had established some modifications of existing tomography models [Ding, 1997]. This model is displayed in Plate 4 and is Grand's model but with his low-velocity anomalies beneath Africa inflated to $-4 \%$. The data are plotted for two events, one beneath Sandwich Island (A) and one beneath the Drake Passage (B). The S, ScS, and SKS phases propagate through the same mantle corridor as the previously discussed events except that they have sampled more of the structure beneath South Africa. Note that the S delay generated by event A increases systematically from about $0 \mathrm{~s}$ at $65^{\circ}$ to $10 \mathrm{~s}$ at $75^{\circ}$. The scatter in data is probably caused by the station delays, which are about this size. Differential times should remove these features, and the $\mathrm{ScS}-\mathrm{S}$ fit is good. In contrast to ScS, SKS starts late and becomes PREM-like at the larger distances, which implies that their paths escape the slow structure by sampling to the east of the anomaly. Note that the anomalous $\mathrm{D}^{\prime \prime}$ in Grand's model has been truncated along its northeastern edge to allow the SKS to become more PREM-like (Plate 1). These data can be fit better by adjusting the structure into a homogeneous block, similar to that displayed in Plate 3 [discussed in Ritsema et al., 1998b].

Synthetics generated from the models in Plate 4 are a little lumpy, as are the observed waveforms, but such complexities could also be caused by the rift system. However, the model suggests a possible detachment just above $\mathrm{D}^{\prime \prime}$. This feature can be tested with more distant stations (Figure 5). Again, we use a Sandwich Island event as recorded by the IRIS stations, FURI and ATD, as presented in Plate 3 . We did not pay much attention to absolute time at these stations because of their wellknown delays. Note that ATD is at the same WWSSN site as AAE, the most anomalous station in the network [Dziewonski and Anderson, 1981]. However, their differential times between S and SKS should be useful since the ray paths are quite close together near the stations. The homogeneous model (ALVS) on the left indicates that $\mathrm{S}$ is delayed relative to SKS, while the model on the right allows both S and SKS to miss the anomaly and be PREM-like-results that do not fit the data. In summary, the data along this corridor support our model with considerable anomalous structure protruding into the mantle. Unfortunately, we do not have such data coverage along other azimuths, although the existing (S-SKS) and ScSS) data from IRIS and older WWSSN networks support this structure [Ni and Helmberger, 2003a]. 

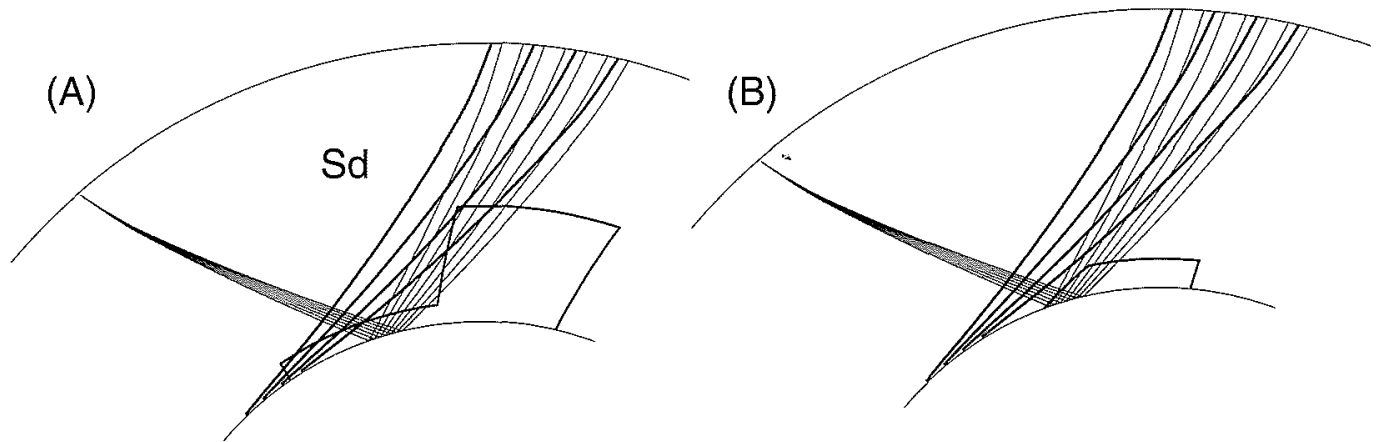

(C)

(D)


(E)

(F)
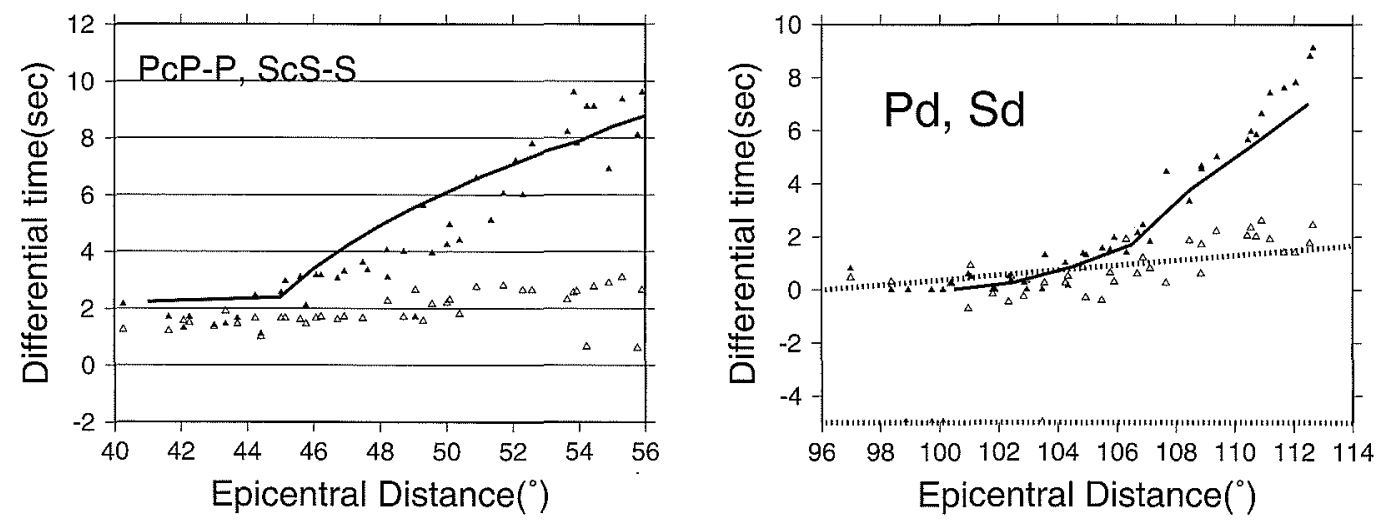
Figure 4. $S_{d}$ record section produced from the Kaapvaal Array, and travel time analysis. (A) $\mathrm{S}_{\mathrm{d}}$ ray paths (heavy lines) and $\mathrm{ScS}$ ray paths (thin lines) sampling a $1200-\mathrm{km}$ structure with a $3 \%$ shear velocity reduction. (B) Same for a $300-\mathrm{km}$ structure with a shear velocity reduction of $2 \%$ on the top and gradually increasing to $12 \%$ at the bottom (ULVD). (C) Waveform data of $\mathrm{S}_{d}$ for event $970610 . \mathrm{S}_{\mathrm{d}}$ shows little delay before $105^{\circ}$, but becomes delayed up to $9 \mathrm{~s}$ at $113^{\circ}$. (D) Travel-time picks of $S_{d}$ (solid symbols) determined by cross-correlation along with travel-time predictions from the two models. The $300-\mathrm{km}$ model fails to explain the $S_{d}$ data because no $S_{d}$ ray paths sample the anomaly (the dotted line shows prediction of the $300-\mathrm{km}$ model). The ALVS model (solid line) fits the $\mathrm{S}_{\mathrm{d}}$ data quite well. Both models can explain the $\mathrm{ScS}$ travel time anomaly, i.e., little delay for small epicentral distances and large delay for large epicentral distances. (E) Comparison of differential PcP-P (PcP travel time minus $\mathrm{P}$ travel time) and ScS-S plots for event 970602. (F) Comparison of $P_{d}$ and $S_{d}$ for this same event, where there is a slight effect on $P_{d}$ and a large effect on $S_{d}$.

\section{STRUCTURAL DEFINITION OF THE EASTERN PROVINCE}

This corridor of Kaapvaal Array data runs mostly along the structure as it bends sharply eastward beneath the Indian Ocean. The western end of the structure is easily seen in the many SKS samples in Plate 2. However, its eastern extension is more difficult to quantify. It appears that adding the SKKS phase can help, as displayed in Plate 5. This phase travels more in the shallow core and has a lower phase velocity than SKS. Thus, it crosses the core-mantle boundary (CMB) further away from the array as displayed. The actual data given in Ni and Helmberger [2003a] have simple waveforms, but the differential timing relative to SKS and SKKS is complicated. While the SKS phase is uniformly late, SKKS shows a pattern as displayed in Plate 5A. This feature can be explained by continuing the eastward bending nature of the structure so that the most southerly paths miss the structure as displayed in the schematic picture (Plate 5B). Several other events that yield slow SKKS values are given in Plate 2. However, this particular event (970525) is special in that the SKKS paths at distances $114^{\circ}-119^{\circ}$ lie along the same SKS paths from a closer event (980325) at $80^{\circ}-85^{\circ}$ (Plate 2A). The latter distance range encloses the S-SKS cross-over, which is easily identified, where $S$ is delayed about the same amount as SKS [Ni and Helmberger, 2003a]. Since S turns about $500 \mathrm{~km}$ (Plate 5B) above the CMB at these ranges, we obtain direct evidence for the elevated structure seen in tomography. Completing the structural image beneath the Indian Ocean proved difficult because of the lack of stations. Thus, we assumed that the basic cross-section determined from the Western Province extends eastern to the boundar- ies, as suggested in some tomography studies (Plate 1). We then tested this model against long-range-diffracted $\mathrm{P}$ and $\mathrm{S}\left(\mathrm{P}_{\mathrm{d}}\right.$ and $\mathrm{S}_{\mathrm{d}}$ ) from events occurring in the western Pacific (Figure 6). Three events proved particularly useful, namely, the northernmost event 971222, the southern event 970904, and the middle one 990206. Record sections from these three events are displayed, plotted as conventional record sections in Figure 6 and as a function of azimuth or as a fan-array in Figure 7. The latter has proven effective in finding salt domes. Obviously, the azimuthal plots organize the data much better than the conventional record sections, proving that this structure is more vertical than horizontal. The bars indicate the relative arrivals where the data are aligned relative to PREM (shifted for range difference). The azimuths are designated with respect to the events; thus, azimuth $246^{\circ}$ is more northerly than $202^{\circ}$. The interpretation is straightforward. Data in column 1 (971222) sample the northern edge, where the arrivals slow down crossing the boundary. The data in the middle column are mostly late, with a slight weakening to the south, ranging from 14 to $18 \mathrm{~s}$ late. The data in column 3 (970904) indicate that the southern boundary is near $214^{\circ}$, but the sloping travel-time curve indicates that the boundary is not parallel to the ray paths, as in Plate 5. The waveforms are also interesting in that they show multiple pulses near the boundaries, $241-246^{\circ}$ (northern) and $212-216^{\circ}$ (southern).

These features can be modeled in several ways. Wen [2001] successfully explained these data by breaking the dataset into narrow sectors (azimuthal groups) and modeling them in 2D. For the upper portion of event 971222 , he modeled the second arrival as a very late $\mathrm{ScS}$ by invoking a very slow $\mathrm{D}^{\prime \prime}$ $(-12 \%$ at the $\mathrm{CMB})$. This anomaly then fades away at the smaller azimuth towards the bottom, where his model of the anomaly becomes thicker but less severe.

The 3D synthetics displayed at the bottom of Figure 7 were constructed from the model presented in Plate 1. These synthetics were generated with a new code called DWKM [Helmberger and $N i, 2004]$. The method uses WKM [Ni et al., 2000] for generation of 2D synthetics and adds out-of-the great-circle-plane arrivals by applying a diffraction operator. An example calculation is displayed in Figure 8. The column on the left displays the great-circle path contribution (2D). One then adds neighboring weighted synthetics to construct the synthetics on the right, which compare well with SEM results [Ni et al., 2005]. Models containing sharp vertical walls generate distorted synthetics for about $2^{\circ}$ to $4^{\circ}$, depending on frequency. Thus, the transition for the 97094 event displayed is probably more sharp than actually modeled, suggesting some horizontal change in shape. The uniqueness issue becomes more serious as we add dimensions to the model, as demonstrated above. The geometry of the ray paths 

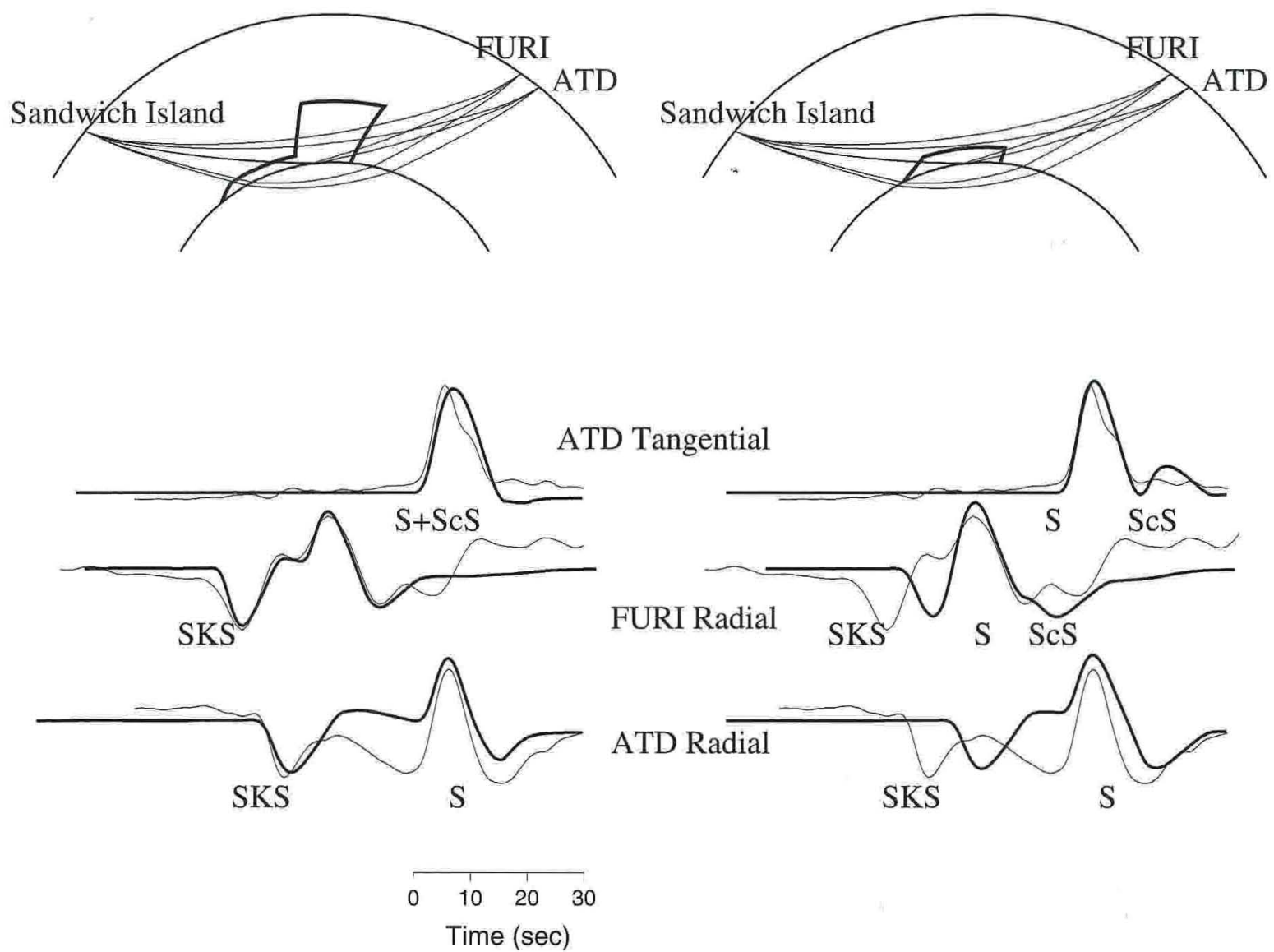

Figure 5. Upper panel: Geometric ray paths sampling the two proposed models, ALVS on the left and the ULVD on the right, at stations FURI $\left(85^{\circ}\right)$ and ATD $\left(89^{\circ}\right)$. The S-wave ray paths sample regions roughly $300 \mathrm{~km}$ above the CMB so that they mostly miss the ULVD structure. The observations are displayed as thin lines relative to the synthetics in heavy lines. Both synthetic S and SKS are PREM-like for the ULVD model, which does not fit the data, whereas the delay of $S$ in ALVS is about right.

sampling the structure also becomes more dependent on the source location. This feature is demonstrated in the third column of Figure 8, where we regenerated the 3D synthetics by allowing the source to move $60 \mathrm{~km}$ to the north. The same effect could have been produced by rotating the ALVS structure by this amount, referred to as ALVSS in the plot. Thus, such sensitivity requires refinement in source locations to accompany structural modeling. Obviously, more data are required to nail down this portion of the structure.

Our model does not explain the edges all that well (there are some misfits between the synthetics and data); however, it does model the long-period response quite well, as discussed in Ni et al. [2005], where data are compared against SEM and DWKM synthetics. Predictions from tomographic models display only about one-third of the travel-time anomaly and are too smooth to produce multipathing. While the $\mathrm{S}$-waves show large noticeable delays with azimuth, the
P-waves are PREM-like (also pointed out earlier by Wen. [2001]). The remoteness of this region and the lack of Indian Ocean events make it difficult to refine the model, although other phases arriving from distant events can be used. For example, the SS phases from the above events (Figure 6) can be used to define the top of the structure, which is compatible with the earlier estimates of the western portion [ $\mathrm{Ni}$ et al., $2003 \mathrm{c}]$. However, only a large sharp structure can produce such rapid changes with azimuth.

\section{DISCUSSION}

The above data analyses provide convincing evidence for a large-scale lower-mantle structure with dimensions of about $1200 \mathrm{~km}$ wide, $1000 \mathrm{~km}$ high, and $7000 \mathrm{~km}$ long. The walls are remarkably sharp, although the SKS delays suggest some complexities, especially along the northeastern edge of the 

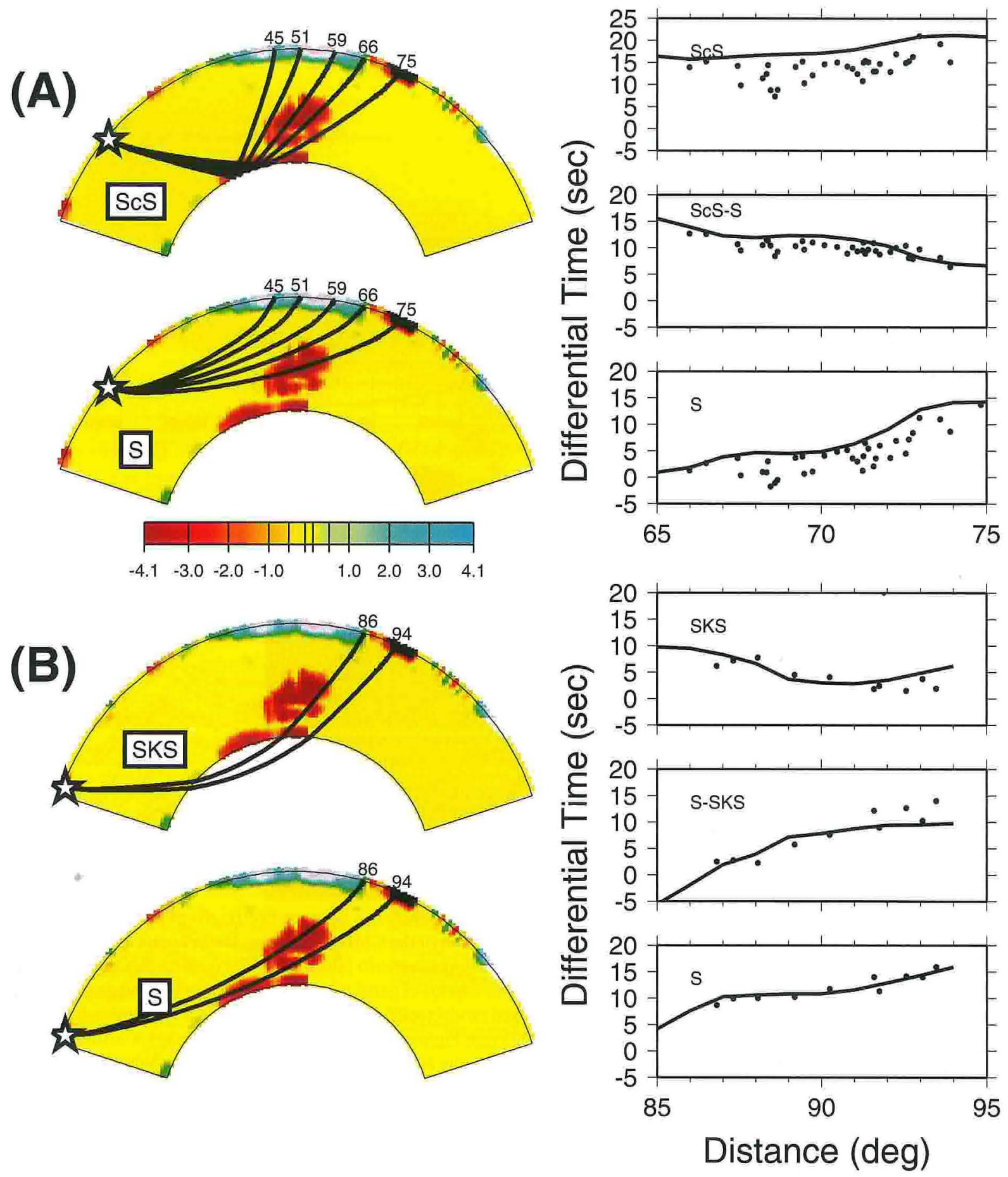

Plate 4. Cross-sections of velocity structure connecting Sandwich Island to the Tanzania Array along with ray paths appropriate for (a) ScS and S and (b) SKS and S. The corresponding travel times on the right were computed from synthetics generated for these 2D sections (solid lines) along with observed picks from the array as discussed by Ritsema et al. [1998b], reduced by PREM. The velocity model was derived from the tomographic images of Grand [1994] by applying an ad hoc enhancement scheme of all anomalies that are beneath Africa increased to $4 \%$, after Helmberger et al. [2000]. 

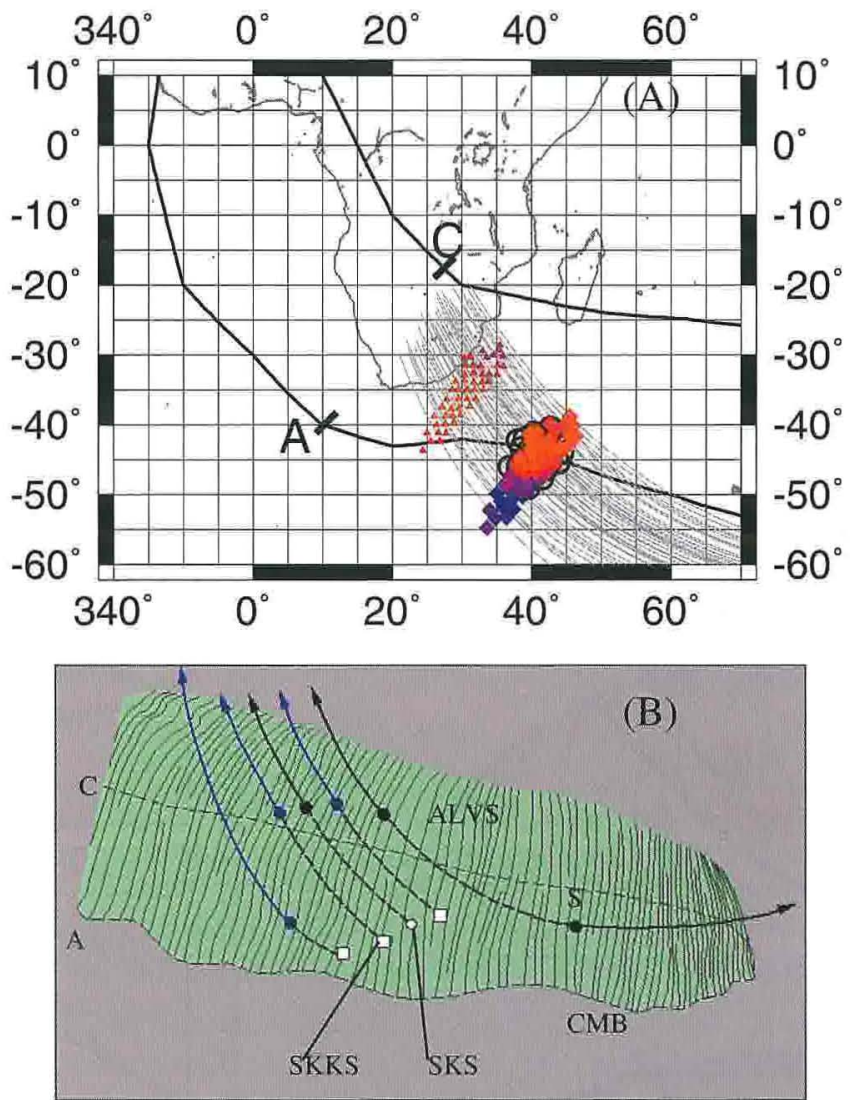

Plate 5. Upper panel: Comparison of SKS and SKKS observations from a western Pacific event (970525) showing the difference in delays apparently caused by the relative position of the CMB exit points. These points are denoted as triangles (SKS) and squares (SKKS). Magenta boxes are delayed relative to blue boxes. The open circles are SKS exit points for event 980325 , which sample the same CMB region. The lower panel (schematic) indicates the unique geometry where ray paths intersect the upper surface of our proposed model (solid circles). Note that SKKS exit points for event 970525 occur at the same location of SKS for event 980325 (see Figure 2). The direct S for the latter event turns at about $500 \mathrm{~km}$ above the CMB and samples the ALVS for about the same amount of path length. The weight lines in the upper panel indicate the ALVS boundary and the CMB, with the Eastern Province starting nears points A and C. 


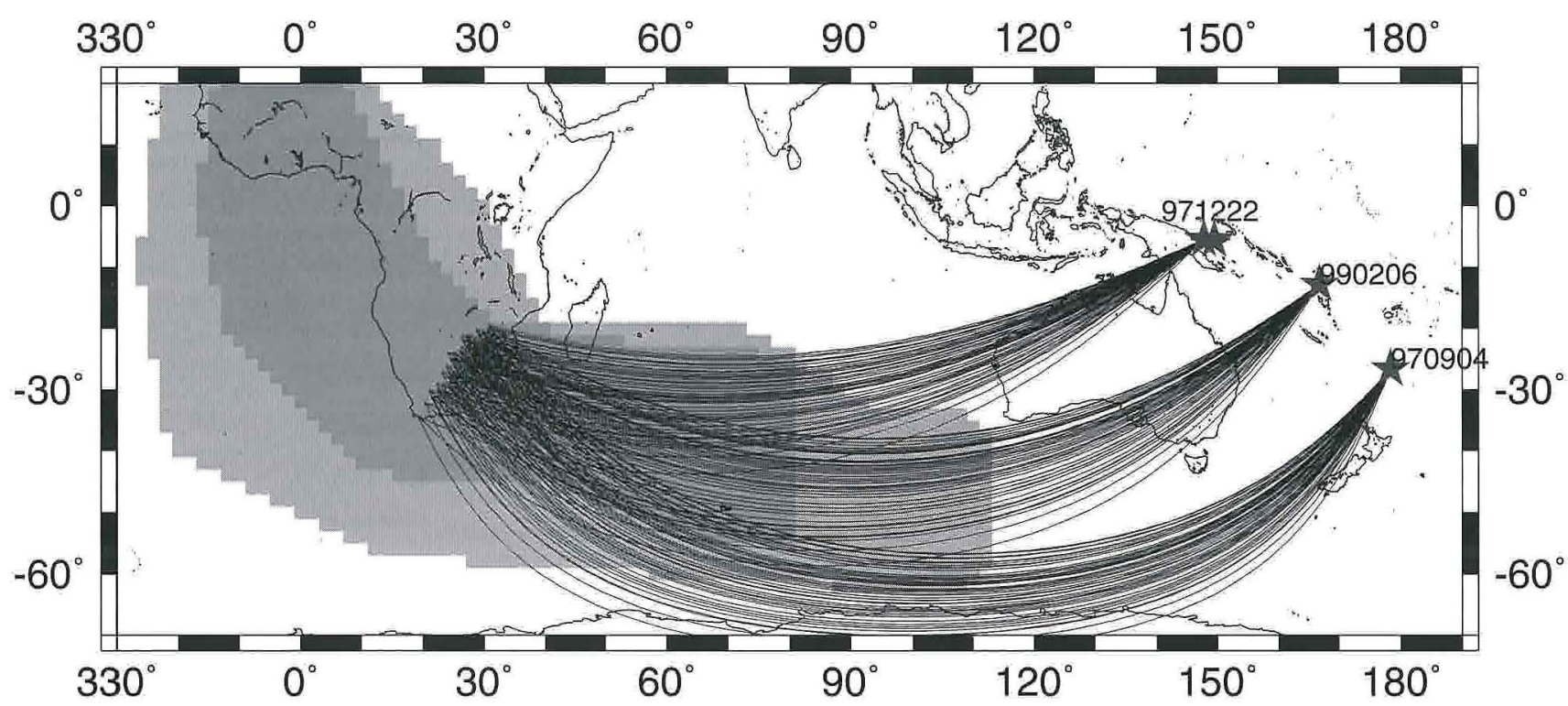

971222

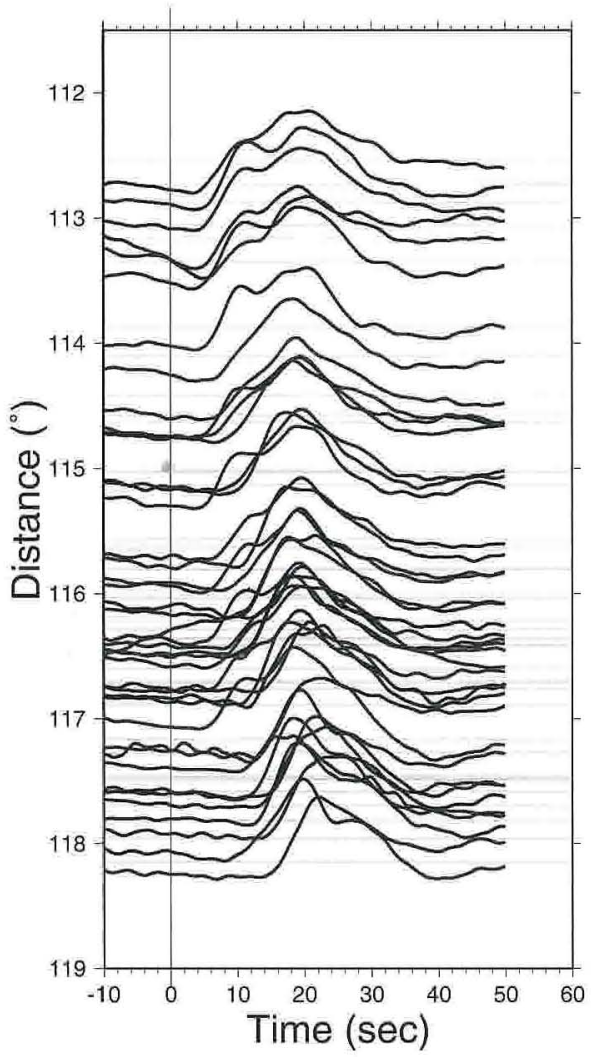

990206

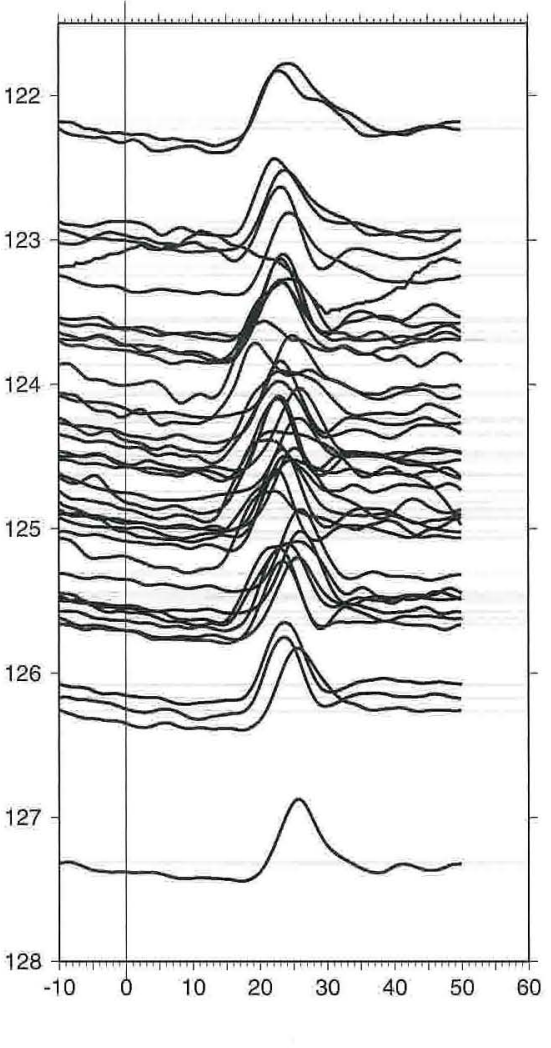

970904

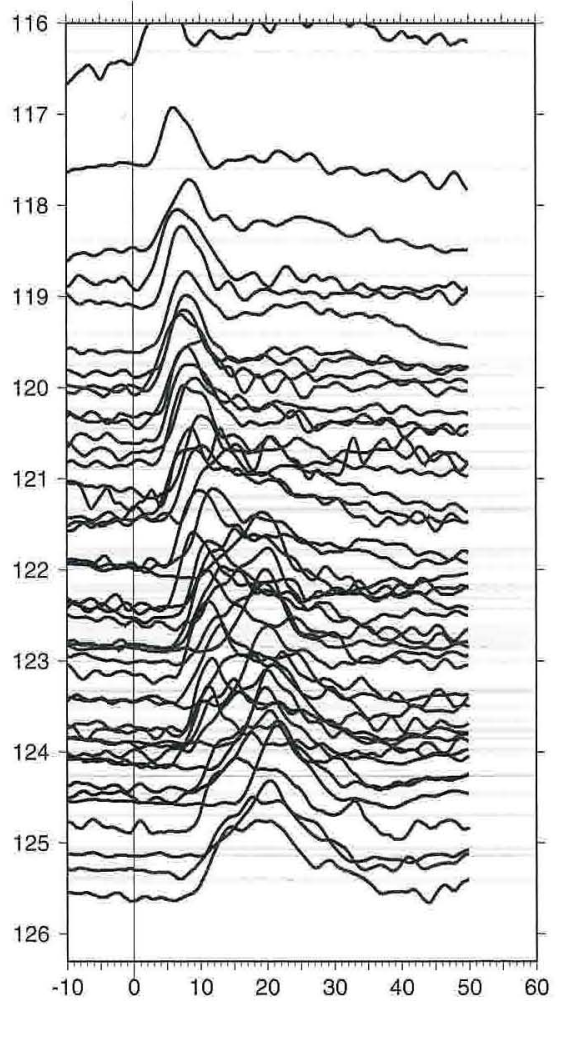

Figure 6. Upper panel: Ray paths of $S_{d}$ as they enter the ALVS model, where event 971222 samples the northern edge and event 970904 samples the southern edge. Paths for event 90206 appear to enter the structure mostly along the axis. Lower panel: The three record sections assembled from the array data. 
971222
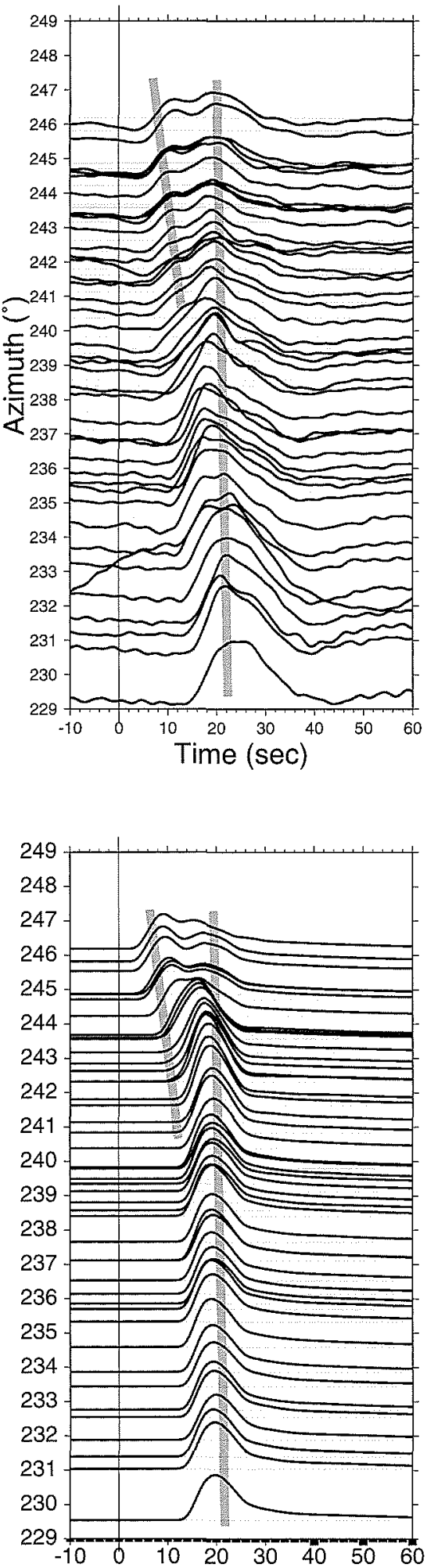

990206


970904
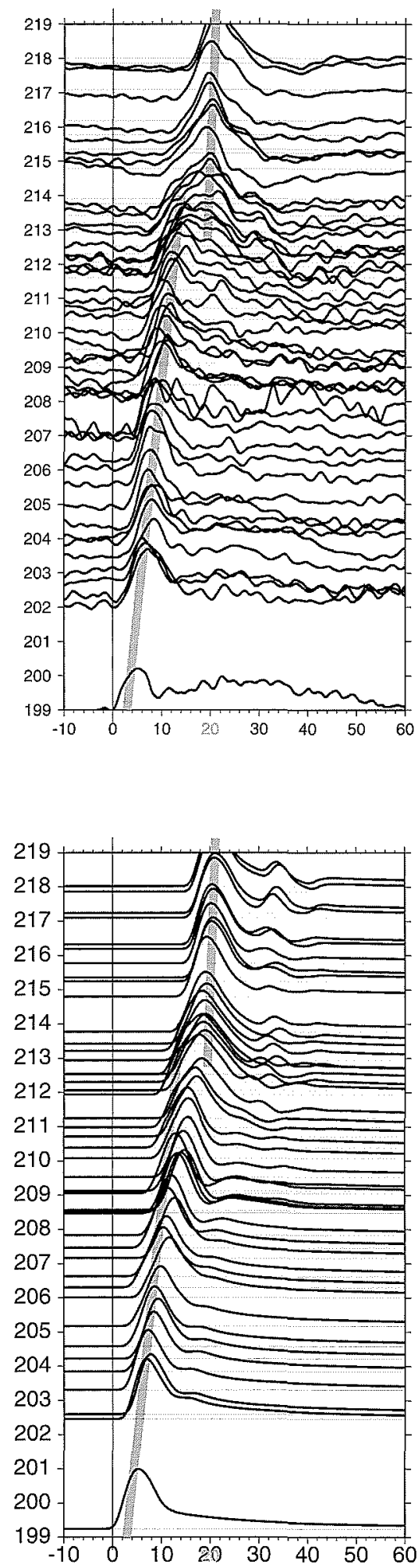
Figure 7. The upper set of observations is a replot of the same data presented in Figure 6 except as a function of azimuth. Heavy lines have been included to highlight the travel times of the multipathing along the boundaries: fast-to-slow at the northern edge (971222) and slow-to-fast at the southern edge (970904). Note that the data approach PREM outside the ALVS and reach delays of $18 \mathrm{~s}$ inside the ALVS. The synthetics (DWKM) based on the model are displayed in the lower panels, aligned relative to PREM predictions.

Western Province. About 10-20\% variability in SKS delays suggests some small-scale extensions above the structure or perhaps some internal structure, such as enhanced percentage drop near its center or in $\mathrm{D}^{\prime \prime}$. Although we favor the large structure over the thinner but more severe velocity drops proposed by Wen [2001] and his colleagues, we must admit that localized strong velocity drops near the edges certainly explain some complex waveforms. However, the above 2D section discussed in detail appears well resolved and is probably representative of the Western Province. The structure beneath the Indian Ocean is less well defined, having only two good samples of thickness, namely, samples of delayed SS starting at a distance of about $125^{\circ}$ [Ni et al., 2005] and one sample of the SKS-S crossover [Ni and Helmberger, 2004]. The Western Province probably tilts to the east, as argued by tomographic images [Ritsema et al., 1999; Ni et al., 2003]. However, the sparse coverage prevents a strong conclusion, and the two models presented in Plate 3 are probably end members bracketing the true structure. Although we have not found any direct evidence for ULVZ beneath the structure, there is ample evidence for a localized ULVZ along the edges. Wen [2000] reports on one between Madagascar and Africa, based on precursors to PKP. Another ULVZ has
$2 \mathrm{D}$

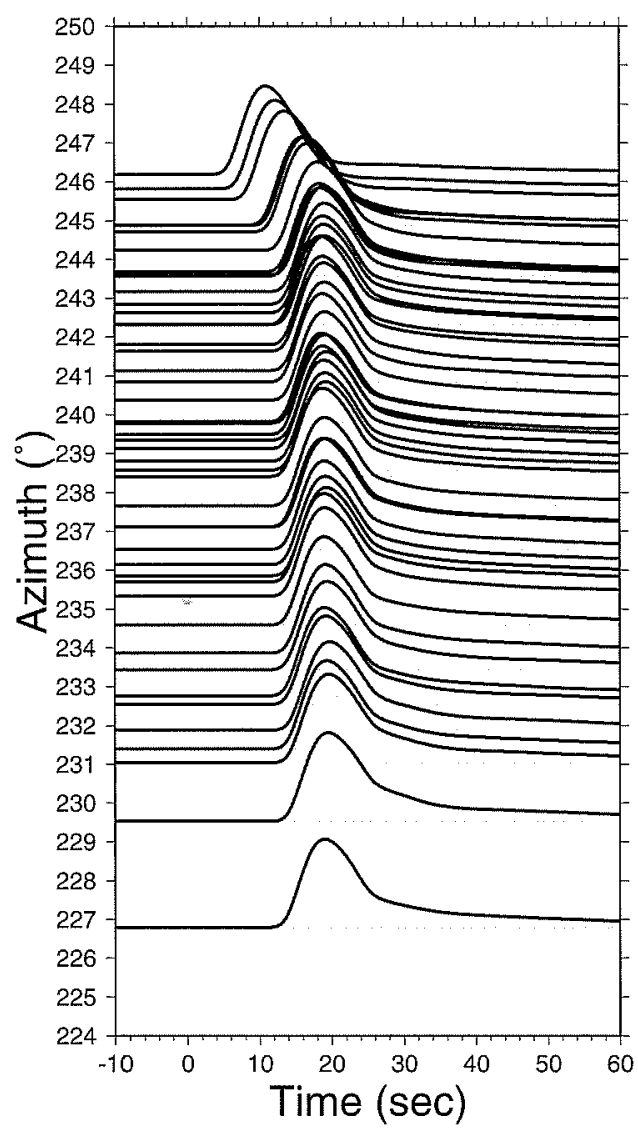

ALVS

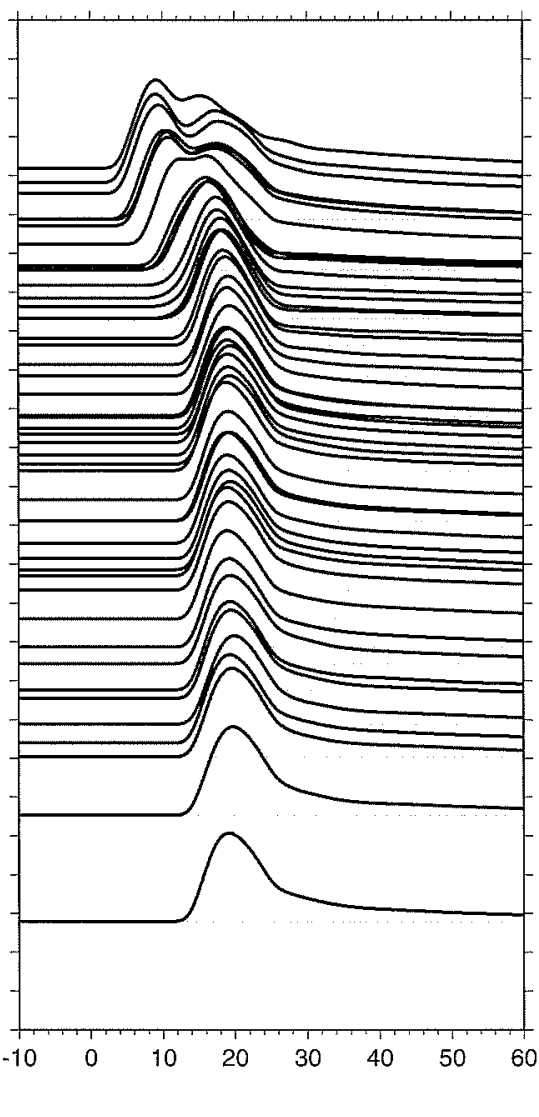

ALVSS



Figure 8. Synthetics generated with the DWKM method. The leftt column contains 2D synthetics produced by constructing a 2D section through the ALVS model presented in Plate 1. The middle column contains contributions from the neighboring paths, assuming an 8-s source duration. The geometry is that shown in Figure 6 for the paths along the northern edge (paths 971222). The right column displays a new set of synthetics with the structure rotated northward by $0.5^{\circ}$ (ALVSS) or moving the source $60 \mathrm{~km}$ to the north. 
two different types of data used to explore its location and dimensions, precursor to PKP [Ni and Helmberger, 2001], and $\mathrm{SKS}_{\mathrm{d}}[$ Helmberger et al., 2000]. This feature is located beneath central Africa. A third ULVZ has been reported beneath Tristan by Ni and Helmberger [2001]. The usual interpretation of ULVZs is that they are partial melt zones [Williams and Garnero, 1996]. This interpretation has gained strength with the recent shockwave data [Akins et al., 2003], suggesting that melt from perovskite probably sinks.

Although many interesting features of the African structure are yet to be determined, our present results have significant implications on seismological studies. For example, a common strategy followed in lower-mantle analyses is to assume that $\mathrm{D}^{\prime \prime}$ is the most likely location for anomalies. It is further commonly assumed that S-wave travel times can be adequately corrected from past tomographic studies and thus ScS-S differential times become an effective means of mapping $D^{\prime \prime}$ (see review by Lay et al. [2003]). Such an approach obviously has serious problems if there are other structures extending upward into the middle mantle, as we argue in this review.

The above presentation on the seismology of this largescale structure and its edges is relatively easy compared to explaining what this structure is and how long has it been there. Although there are many possibilities, two candidates have been addressed with considerable analyses [Tackley, $2000]$. One is the Primitive Layer model introduced by Kellogg et al. [1999], who argue that this layer contains the stuff needed for "isotopic mixing" and heat production and that it has been there billions of years. Unfortunately, recent seismic studies have not indicated much evidence for a global layer [Castle and van der Hilst, 2003], although it does not eliminate regional structures as displayed here. A second version of the primitive layer hypothesis is that of Primitive Piles [Tackley, 2000]. He suggests that the two so-called megaplumes beneath the Pacific and South Africa are constructed from primitive materials that, again, are old. Convection studies on these two models suggest that this material is relatively dense, contrasts of $1-2 \%$, along with excess temperatures, being compatible with supposed shapes [Ni et al., 2002]. These density estimates are compatible with the combination of gravity anomalies and normal-mode data [Ishii and Tromp, 1999]. Excess temperature is more difficult to establish, but the excellent correlation between the geoid and our structure (Plate 2) would provide the ideal geometry for the Gondwanaland breakup [Davaille, 1999]. That is, these "piles" are expected to have hot thermal upwelling arising from their tops and perhaps edges [Gonnermann et al., 2002]. Such upwelling then would explain the so-called Dupal isotope anomaly (see also Plate 2 and Hart [1984]).
However, the issue of a radioactive-rich layer at the base of the mantle as suggested by Kellogg et al. [1999] is disputed by Anderson [2001, 2002]. Anderson argues that such regions would overheat and overturn, delivering their radioactive elements to the upper mantle. Essentially, the accretionary process leaves the lower mantle as a drain for the denser metallic melts and refractory material. He suggests that this chemically distinct structure would have a low thermal expansivity, along with high conductivity and viscosity, and that this structure would develop irregular shapes caused by sluggish behavior (low Rayleigh number convection). This image also seems compatible with the above seismic observations. However, the top of this structure would again be hot and would supply a great deal of heat to the middle mantle.

In short, while these interpretations are all interesting, a great deal of seismology, geodynamics, and geochemical modeling is required to understand this new class of lowermantle structure and its role in plate tectonics, if any.

Acknowledgments. We thank Lianxing Wen and Ed Garnero for their excellent reviews, Evelina Cui for her efforts in producing this manuscript, and the editors of this book, in particular, Rob van der Hilst and production coordinator Virginia Marcum. This research was supported by NSF Grant EAR-0229885. Contribution Number 9116 of the Division of Geological and Planetary Sciences, California Institute of Technology.

\section{REFERENCES}

Akins, J. A., T. J. Ahrens, and P. D. Asimow, Shock-induced melting of $\mathrm{MgSiO}_{3}$ (perovskite): Implications for density of ultramafic liquids above core-mantle boundary, Abstract, Eos Trans. AGU., 84 (46), 2771, 2003.

Anderson, D. L., Top-down tectonics, Science, 293, 2016, 2001.

Anderson, D. L., The case for irreversible chemical stratification of the mantle, Int. Geol. Rev., 44, 97-116, 2002.

Castle, J. C. and R. van der Hilst, Searching for seismic scattering off mantle interface between $800 \mathrm{~km}$ and $2000 \mathrm{~km}$ depth, $J$. Geophys. Res., 108 (B2), 2095, 2003.

Davaille, A., Simultaneous generation of hotspots and superswells by convection in a heterogeneous planetary mantle, Nature, 402 , 756-760, 1999.

Ding, Xiaoming, High resolution studies of deep earth structure, Ph.D. Thesis, California Institute of Technology, Pasadena, California, 1997.

Dziewonski, A. M. and D. L. Anderson, Preliminary Reference Earth model, Phys. Earth Planet. Inter., 25, 297-356, 1981.

Garnero, E. J., Lower mantle heterogeneity, Ann. Rev. Earth Planet. Sci., 28, 509-537, 2000.

Gonnermann, H. M., M. Manga, A. M. Jellinek, Dynamics and longevity of an initially stratified mantle, Geophys. Res. Lett., $29,1029,2002$ 
Grand, S. P., Mantle shear structure beneath the Americas and surrounding oceans, J. Geophys. Res., 99, 11,591-11,622, 1994.

Grand, S. P., R. D. van der Hilst, and S. Widiyantoro, Global seismic tomography: Global seismic tomography: A snapshot of convection in the Earth, GSA Today, 7, 1-7, 1997.

Grand, S. P., Mantle shear-wave tomography and the fate of subducted slabs, Phil. Trans. R. Soc. Lond., A, 360, 2475-2491, 2002.

Hager, B. H., R. W. Clayton, M. A. Richards, R. P. Comer, and A. M. Dziewonski, Lower mantle heterogeneity; dynamic topography and the geoid, Nature, 313, 541-545, 1985.

Hart, S., A large-scale isotope anomaly in the Southern Hemisphere Mantle, Nature, 309, 753-757, 1984.

Helmberger, D. V., S. Ni, L. Wen, and J. Ritsema, Seismic evidence for ultra low-velocity zones beneath Africa and Eastern Atlantic, J. Geophys. Res., 105 (B10), 23865-23878, 2000.

Helmberger, D. V. and S. Ni, Approximate 3D Bodywave Synthetics for Tomographic Models, submitted to Bull. Seismol. Soc. Am., 2004.

Ishii, M. and J. Tromp, Normal-mode and free-air gravity constraints on lateral variations in velocity and density of Earth's mantle, Science, 285, 1231-1236, 1999.

James, D. E., M. J. Fouch, J. C. VanDecar, S. van der Lee, Kaapvaa1 Seismic Group, Tectospheric structure beneath southern Africa, $G R L, 28,2485-2488,2001$.

Kellogg, L., B. H. Hager, and R. vanderHilst, Compositional Stratification in the Deep Mantle, Science, 283, 1881-1884, 1999.

Lay, T., E. J. Garnero, and Q. Williams, Partial Melting in a Thermo-Chemical Boundary Layer at the Base of the Mantle, submitted to Phys. Earth Planet. Inter., 2003.

Masters, G., G. Laske, H. Bolton, and A. M. Dziewonski, The relative behavior of shear velocity, bulk sound speed, and compressional velocity in the mantle: Implications for chemical and thermal structure, in Earth's Deep Interior: Mineral Physics and Tomography From the Atomic to the Global Scale, eds. S. Karato, A. M. Forte, R. C. Liebermann, G. Masters, and L. Stixrude, $A G U, 63-87$, Washington, DC., USA., 2000.

Ni, S., X. Ding, and D. V. Helmberger, Constructing synthetics from deep earth tomographic models, Geophys. J. Int., 140 , 71-82, 2000.

$\mathrm{Ni}$, S., and D. V. Helmberger, Horizontal transition from fast (slab) to slow (plume) structures at the core-mantle boundary, Earth Planet. Sci. Lett., 187, 301-310, 2001.

Ni, S., E. Tan, M. Gurnis, and D. V. Helmberger, Sharp Sides to the African Super Plume, Science, 296, 1850-1852, 2002.

Ni, Sidao and D. V. Helmberger, Seismological Constraints on the South African Super Plume; could be the oldest distinct structure on Earth, Earth Planet. Sci. Lett., 206, 119-131, 2003a.

$\mathrm{Ni}$, Sidao and D. V. Helmberger, Ridge-like lower mantle structure beneath South Africa, J. Geophys. Res., 108, 2094-2110, $2003 b$.
Ni, Sidao and D. V. Helmberger, Further constraints on African Super Plume Structure, Phys. Earth Planet. Inter., 140, 243-251, $2003 \mathrm{c}$.

Ni, Sidao, Vernon F. Cormier, and D. V. Helmberger, A Comparison of Synthetic Seismograms for 2D Structures: Semianalytical versus Numerical, Bull. Seismol. Soc. Am., 93, No. 6, 2752-2757, 2003 d.

Ni, Sidao, D. V. Helmberger, and J. Tromp, Three-dimensional structure of the African superplume from waveform modeling, Geophys. J. Int., 161, 283-294, 2005.

Nyblade, A. A., C. Birt, C. A. Langston, T. J. Owens, and R. Last, Seismic experiment reveals rifting of craton in Tanzania, Eos Trans. $A G U, 77,517-521,1996$.

Ritsema, J., S. Ni, D. V. Helmberger, and H. P. Crotwell, Evidence for strong shear velocity reductions and velocity gradients in the lower mantle beneath Africa, Geophys. Res. Lett., 25, 4245-4248, 1998a.

Ritsema, J., A., A. Nyblade, T. J. Owens, C. A. Langston, and J. C. VanDecar, Upper mantle seismic velocity structure beneath Tanzania, J. Geophys. Res., 103, 21,201-21,213, 1998 b.

Ritsema, J., H. Van Heijst, and J. Woodhouse, Complex shear wave velocity structure imaged beneath Africa and Iceland, Science, $286,1925-1928,1999$

Simmons, N. A. and S. P. Grand, Partial melting in the deepest mantle, Geophys. Res. Lett., 1552, 2002.

Tackley, P., Mantle Convection and Plate tectonics: Toward an integrated Physical and Chemical Theory, Science 288, 2002-2007, 2000

van der Hilst, R., S. Widiyantoro, E. R. Engdahl, Evidence for deep mantle circulation from global tomography, Nature, 386 , $578-584,1996$.

van der Hilst, R., J. Tromp, and E. Stutzman, Seismological Constraints on Mantle Structure and Composition, Nature, 2004.

Wang, Y. and L. Wen, Mapping the geometry and geographic distribution of a very low velocity province at the base of the Earth's mantle, J. Geophys. Res., 109, B10305, 2004.

Wen, L., Intense seismic scattering near the Earth's core-mantle boundary beneath the Comoros hotspot, Geophys. Res. Lett., 27, 3627-3630, 2000.

Wen, L., Silver P, James D and Kuehnel R., Seismic evidence for a thermo-chemical boundary at the base of the Earth's mantle, Earth Planet. Sci. Lett., 189, 141-153, 2001.

Wen, L., Seismic evidence for a rapidly varying compositional anomaly at the base of the Earth's mantle beneath the Indian Ocean, Earth Planet. Sci. Lett., 194, 83-95, 2001.

Williams, Q. and E. J. Garnero, Seismic evidence for partial melt at the base of the Earth's mantle, Science, 273, 1528-1530, 1996.

D. V. Helmberger and S. Ni, Seismological Laboratory, California Institute of Technology, Pasadena, California, USA. (helm@) gps.caltech.edu) 